05

\title{
Перенос голографической структуры со слоев бихромированного желатина на подложку на основе полиметилметакрилата
}

\author{
(C) Н.М. Ганжерли ${ }^{1}$, С.Н. Гуляев ${ }^{2}$, И.А. Маурер ${ }^{1}$, Д.Р. Хазвалиева ${ }^{2}$ \\ ${ }^{1}$ Физико-технический институт им. А.Ф. Иоффре, \\ 194021 Санкт-Петербург, Россия \\ ${ }^{2}$ Санкт-Петербургский политехнический университет Петра Великого, \\ 195251 Санкт-Петербург, Россия \\ e-mail: nina.holo@mail.ioffe.ru
}

Поступила в редакцию 25.10.2017 г.

\begin{abstract}
Показана возможность переноса голографической структуры, первоначально зарегистрированной на слоях бихромированного желатина (БХЖ), на материал подложки из полиметилметакрилата (ПММА). В основе механизма образования вторичной рельефно-фазовой голографической структуры на поверхности ПММА лежит использование избирательного деструктивного воздействия коротковолнового УФ излучения с длиной волны менее $270 \mathrm{~nm}$. Осуществлены оптимизация режимов обработки и подбор проявляющих составов на основе изопропанола и метилизобутилкетона (МИБК), что позволило создать на подложках из ПММА рельефно-фазовые голографические решетки с высокой дифракционной эффективностью (ДЭ) около $25 \%$ и максимальной глубиной поверхностного рельефа порядка $1 \mu \mathrm{m}$.
\end{abstract}

DOI: $10.21883 /$ OS.2018.03.45660.246-17

\section{Введение}

Один из наиболее эффективных методов преобразования амплитудных голографических структур, зарегистрированных на галоидосеребряных фотослоях, в рельефно-фазовые основан на деструктивном воздействии коротковолнового УФ излучения на желатин фотоэмульсий [1]. Поскольку основным компонентом слоев БХЖ также является желатин, данный метод можно применить в отношении этой регистрирующей голографической среды. Результаты ранее проведенных исследований [2] показали, что причиной формирования глубокого поверхностного рельефа на БХЖ является переменная задубленность слоя, возникающая при регистрации интерференционной картины когерентным излучением на длине волны $0.44 \mu \mathrm{m}$ и служащая фактором, модулирующим деструктивное воздействие коротковолнового УФ излучения на желатин. В работах $[2,3]$ показано, что облучение УФ излучением слоев БХЖ с записанными на них голографическими структурами и удаление фотодеградированных участков желатина водой приводит к десятикратному увеличению высоты поверхностного рельефа как на толстых $\left(T_{\mathrm{avr}} \geq 50 \mu \mathrm{m}\right)$, так и на тонких $\left(T_{\text {avr }} \leq 3 \mu \mathrm{m}\right)$ слоях. На сверхтонких слоях БХЖ со средней толщиной $T_{\text {avr }}<0.7 \mu \mathrm{m}$ удалось получить голографические решетки с ДЭ $30 \%$, приближающейся к теоретическому пределу для тонких рельефно-фазовых голограмм. При этом было установлено, что при переходе от толстых к сверхтонким слоям энергетическая чувствительность БХЖ практически не изменяется. Также было показано [3], что увеличение времени облучения коротковолновым УФ излучением сверхтонких слоев $\left(T_{\mathrm{avr}}<1 \mu \mathrm{m}\right)$ или многократное повторение цикла „УФ облучение-промывка-сушка“ в от- ношении слоев средней толщины $\left(T_{\mathrm{avr}}<6 \mu \mathrm{m}\right)$ ведет к образованию окон, в области которых толщина слоя БХЖ $T \rightarrow 0$. Таким образом, если вместо стекла, обычно используемого в качестве подложки, выбрать иной материал, имеющий достаточную чувствительность к коротковолновому УФ излучению и обладающий высокими оптическими характеристиками, возможно осуществить перенос голографической структуры со слоя БХЖ непосредственно на материал подложки. В настоящей работе в качестве материала подложки выбран полиметилметакрилат (ПММА).

ПММА как промышленный материал широко доступен, легко обрабатываем и имеет высокую прозрачность, что позволяет изготавливать из него самые разнообразные оптические элементы. С другой стороны, он обладает достаточно высокой чувствительностью к различного рода излучениям, что предопределило его широкое использование как резиста для электронно-лучевой литографии и рентгеновской литографии с высоким разрешением [4,5]. ПММА также применяется в качестве позитивного фоторезиста для коротковолнового УФ излучения $(\lambda \leq 300 \mathrm{~nm})$ [5-7], т. е. в области спектра излучения ртутных ламп, которые применялись для облучения образцов в работах $[2,3]$. Исходя из вышеизложенного перенос голографической структуры на поверхность подложки из органического материала возможно осуществить, последовательно применяя технологию обработки слоев БХЖ и технологию обработки фоторезистов. Применение БХЖ в данном случае оправдано, поскольку энергетическая чувствительность материала лежит в пределах $50-500 \mathrm{~mJ} / \mathrm{cm}^{2}$ для видимого диапазона длин волн $\lambda=0.44-0.63 \mu \mathrm{m}[8]$, в котором существуют высококачественные когерентные источники излучения, использующиеся в голографии. 
Энергетическая чувствительность ПММА в диапазоне коротковолнового УФ излучения с $\lambda \leq 270 \mathrm{~nm}$ составляет $\geq 250 \mathrm{~mJ} / \mathrm{cm}^{2}$ [5], где использование лазеров для голографии ограничено вследствие их низкой когерентности и дороговизны оптических элементов. Поэтому эксперименты по голографической записи на композите „БХЖ + ПММА“ являются основной задачей настоящей работы, поскольку могут иметь применение в виде непосредственного формирования пространственнопериодических структур на поверхности органического полимера.

\section{Эксперимент}

В качестве объекта исследования нами были выбраны голографические дифракционные решетки с пространственной частотой, близкой к $100 \mathrm{~mm}^{-1}$, которые регистрировались на слоях БХЖ, нанесенных на подложки из ПММА толщиной $2 \mathrm{~mm}$. Голографическая запись решеток осуществлялась по симметричной оптической схеме излучением $\mathrm{He}-\mathrm{Cd}$-лазера с длиной волны $0.44 \mu \mathrm{m}$ и мощностью $12 \mathrm{~mW}$.

Слои БХЖ изготавливались в лабораторных условиях подобно способу, предложенному Шенкоффом [9]. В зависимости от количества исходного раствора желатина с бихроматом аммония и степени его разбавления можно было изменять толщину политых слоев БХЖ от долей до единиц микрона [3]. В ходе экспонирования решеток в слое БХЖ происходило фотолитическое избирательное задубливание желатины за счет образования комплексов $\mathrm{Cr}^{+3}$. После экспонирования образцы обрабатывались купанием в 2\%-ном растворе сульфита натрия $\mathrm{Na}_{2} \mathrm{SO}_{3}$ в течение $5 \mathrm{~min}$ для завершения процессов дубления желатина и удаления соединений хрома из слоя БХЖ. Далее следовала окончательная промывка в течение $20 \mathrm{~min}$ в проточной воде и сушка при комнатной температуре. В дальнейшем производилась процедура облучения образцов УФ излучением ртутно-кварцевой лампы высокого давления ДРТ-220 в течение 7-50 $\mathrm{min}$ и последующей промывки в воде. В результате этой операции незадубленные участки желатинового слоя, находившиеся в минимумах интерференционной картины, подвергались фотолизу и удалялись растворением в воде комнатной температуры, что позволяло сформировать в слое БХЖ окна для последующего воздействия УФ излучения на материал подложки ПММА. Для относительно толстых слоев БХЖ (несколько микрон) операция „засветка УФ излучением + купание в воде“ повторялась неоднократно, раз за разом понижая среднюю толщину слоя, чтобы обеспечить доступ УФ излучения к материалу подложки.

Последняя стадия эксперимента заключала в себе механическое удаление с поверхности подложки желатиновых слоев, предварительно размоченных в горячей воде при температуре $45^{\circ} \mathrm{C}$ и обработку собственно ПММА. Следует отметить, что в отличие от слоев БХЖ, в которых фотодеградированные участки желатины вымываются водой, разрушенные УФ излучением участки ПММА требуют специальных травящих составов - проявителей. В литографии для резистов на основе ПММА наиболее сильным проявителем является чистый метилизобутилкетон (МИБК). Также используются смеси „МИБК + изопропанол“ $(1: 3)$, чистый изопропанол, смесь „изопропанол + вода“ $(1: 1)$, ацетон и др. $[4,5,7,10,11]$. В более ранней работе [3] обработка подложки из ПММА в специальном проявителе отсутствовала, что не позволило получить высоту поверхностного рельефа более $0.18 \mu \mathrm{m}$, а величину средней ДЭ более $10 \%$. Поэтому в настоящей работе на завершающей стадии эксперимента использовались все перечисленные составы специальных проявителей для резистов на основе ПММА. Время проявления составляло 20-120s. После операции проявления следовала промывка в двух ваннах чистого изопропанола.

После обработки образцов измерялись такие параметры голографических решеток, как высота поверхностного рельефа $h$ и дифракционная эффективность $\eta$ в 1-м и нулевом порядках дифракции. Высота поверхностного рельефа измерялась с помощью микроинтерферометра МИИ-4 как полный перепад между гребнями и впадинами. ДЭ определялась как отношение интенсивности пучка того или другого порядка дифракции, прошедшего через голограмму, к интенсивности падающего пучка для длины волны $\mathrm{He}-\mathrm{Ne}$-лазера $0.63 \mu \mathrm{m}$.

\section{Результаты}

На образцах с первоначальной толщиной слоя БХЖ $T_{\mathrm{avr}} \approx 3.5 \mu \mathrm{m}$ был проведен пробный эксперимент, включающий проявление подложки ПММА в проявителях разного состава после механического удаления слоя БХЖ. Проявление и промывка образца осуществлялись ватными палочками, смоченными в жидкости. Время проявления составляло $1 \mathrm{~min}$ для всех четырех вариантов проявляющих растворов. Время экспонирования слоев БХЖ когерентным излучением $t_{\mathrm{He}-\mathrm{Cd}}$ варьировалось в пределах 30-80s. Для окончательного формирования рельефной структуры на поверхности подложки понадобилось четыре засветки образца коротковолновым УФ излучением с временами 23, 24, 23 и $40 \mathrm{~min}$. Данные по пробному эксперименту сведены в табл. 1. В этой таблице, как и во всех последующих, приведены максимально достигнутые значения ДЭ в 1-м порядке дифракции и минимальные значения ДЭ нулевого порядка, характеризующего долю прошедшего и не рассеянного голографической структурой света. Как видно из табл. 1, при применении проявляющих составов, содержащих чистый изопропанол, получены наилучшие результаты как по высоте поверхностного рельефа, составившей величину $1.2 \mu \mathrm{m}$, что в 6 раз превышает достигнутую ранее в работе [3] максималь- 
Таблица 1. Параметры голографических решеток на подложках ПММА (пробный эксперимент)

\begin{tabular}{l|c|c|c|c}
\hline \multicolumn{1}{c|}{ Проявитель } & Промывка & $\begin{array}{c}\text { Высота } \\
\text { рельефа } h, \mu \mathrm{m}\end{array}$ & $\begin{array}{c}\text { ДЭ в нулевом } \\
\text { порядке } \eta_{0}, \%\end{array}$ & $\begin{array}{c}\text { ДЭ в } 1 \text {-м } \\
\text { порядке } \eta_{1}, \%\end{array}$ \\
\hline Ацетон $(100 \%)$ & $\mathrm{H}_{2} \mathrm{O}$ & 0.2 & 43.7 & 3.9 \\
Изопропанол $+\mathrm{H}_{2} \mathrm{O} 1: 1$ & $\mathrm{H}_{2} \mathrm{O}$ & 0.18 & 88.2 & 3.7 \\
Изопропанол $(100 \%)$ & - & 0.98 & 7.1 & 11.2 \\
Изопропанол $(100 \%)$ & $\mathrm{H}_{2} \mathrm{O}$, далее & 1.2 & 4.8 & 12.2 \\
& изопропанол $(100 \%)$ & & &
\end{tabular}

Таблица 2. Параметры обработки образцов в ваннах (основной эксперимент)

\begin{tabular}{c|l|l|c|c}
\hline \multirow{2}{*}{ № } & \multicolumn{1}{|c|}{ Проявитель } & Промывка & $\begin{array}{c}\text { Начальная толщина } \\
\text { слоя БХЖ, } \mu \mathrm{m}\end{array}$ & $\begin{array}{c}\text { Время засветки } \\
\text { УФ излучением, тіп }\end{array}$ \\
\hline 1 & Изопропанол (100\%) $[1 \mathrm{~min}]$ & Изопропанол $(100 \%)[1 \mathrm{~min}]$ & 0.3 & $7+54$ \\
2 & МИБК+ изопропанол $1: 1[1 \mathrm{~min}]$ & Изопропанол $(100 \%)[30+30 \mathrm{~s}]$ & 1.5 & $25+25$ \\
3 & МИБК + изопропанол $1: 1[20 \mathrm{~s}]$ & Изопропанол $(100 \%)[15+15 \mathrm{~s}]$ & 5 & $23+23+45$
\end{tabular}

Таблица 3. Параметры голографических решеток на подложках ПММА (основной эксперимент)

\begin{tabular}{c|c|c|c}
\hline № & $\begin{array}{c}\text { Высота } \\
\text { рельефа } h, \mu \mathrm{m}\end{array}$ & $\begin{array}{c}\text { ДЭ в 0-м } \\
\text { порядке } \eta_{0}, \%\end{array}$ & $\begin{array}{c}\text { ДЭ в 1-м } \\
\text { порядке } \eta_{1}, \%\end{array}$ \\
\hline 1 & 0.48 & 54 & 8 \\
2 & - & 10.3 & 15.3 \\
3 & 1.3 & 1.7 & 25
\end{tabular}

ную высоту поверхностного рельефа, так и по величине максимальной ДЭ.

Очевидно, что более качественные и стабильные результаты можно получить, применяя процесс проявления подложек ПММА в ваннах. В последующих экспериментах мы использовали как чистый изопропанол, так и более сильный растворитель МИБК. Параметры обработки, начальная толщина слоев БХЖ и длительность каждой операции (в квадратных скобках) для трех образцов указаны в табл. 2. Время экспонирования слоев БХЖ когерентным излучением $t_{\mathrm{He}-\mathrm{Cd}}$ варьировалось в пределах 5-180s.

Параметры голографических решеток на подложках ПММА, полученных в результате проявления в ваннах, приведены в табл. 3. Как видно из табл. 2 и 3, применение в качестве проявителя чистого изопропанола (образец № 1) позволяет осуществить успешный перенос голографической структуры на материал подложки даже в случае сверхтонкого слоя БХЖ с $T_{\mathrm{avr}} \approx 0.3 \mu \mathrm{m}$. На поверхности ПММА получена значительная высота поверхностного рельефа $h=0.48 \mu \mathrm{m}$, а решетка характеризуется заметным значением ДЭ в 1-м порядке $\eta_{1}$, равным $8 \%$.

При использовании более сильного проявителя МИБК, разбавленного изопропанолом, и более толстого слоя БХЖ $T \approx 1.5 \mu \mathrm{m}$ (образец № 2) удалось повысить
ДЭ структуры в 1-м порядке почти в 2 раза. Однако неоднородности травления, возникшие при сравнительно большом времени проявления (1 $\mathrm{min})$, не дали возможность измерить высоту поверхностного рельефа в интерферометре МИИ-4 из-за нарушения регулярности голографической структуры.

Проблему удалось решить, существенно сократив время проявления до $20 \mathrm{~s}$ (образец № 3). При этом были получены правильные регулярные рельефные структуры (рис. 1), обладающие высокой ДЭ в 1-м порядке до $25 \%$ и малой долей нерассеянного света порядка $1.7 \%$. Высота поверхностного рельефа проявленных подложек ПММА в несколько раз превышает эту величину для непроявленных образцов (рис. 2), что доказывает эффек-

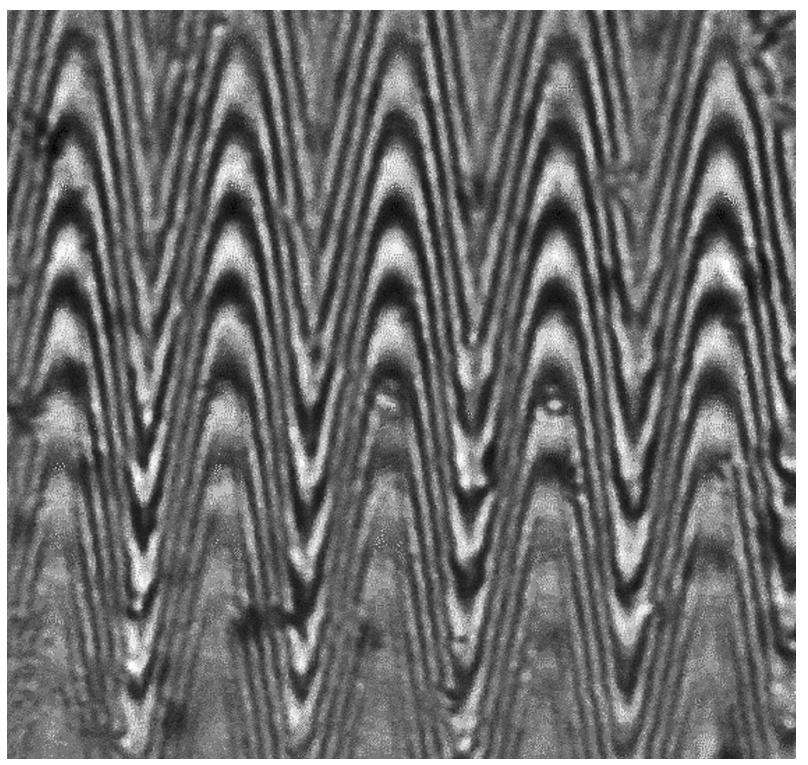

Рис. 1. Интерферограмма поверхностного рельефа подложки ПММА. 


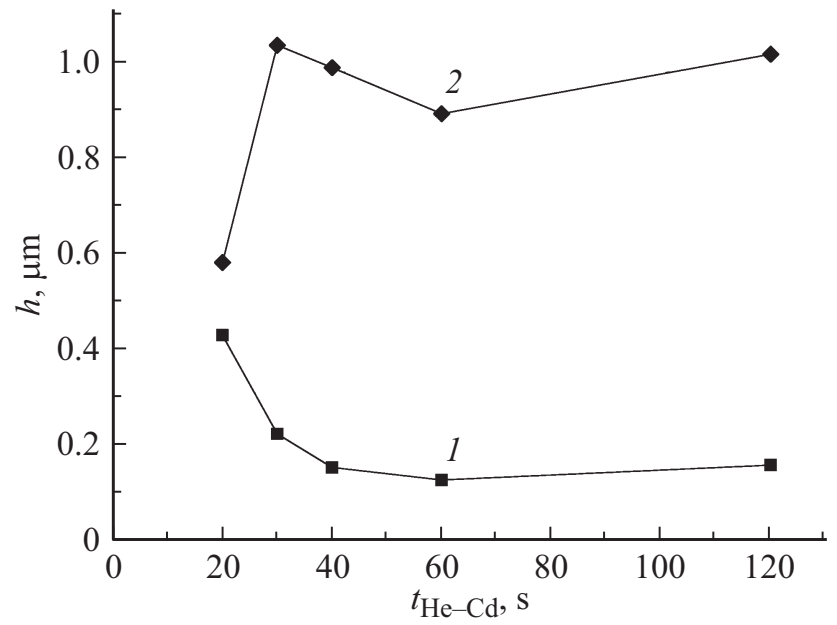

Рис. 2. Зависимость высоты поверхностного рельефа от времени экспонирования БХЖ когерентным излучением для непроявленных (кривая 1) и проявленных (кривая 2) подложек ПММА.

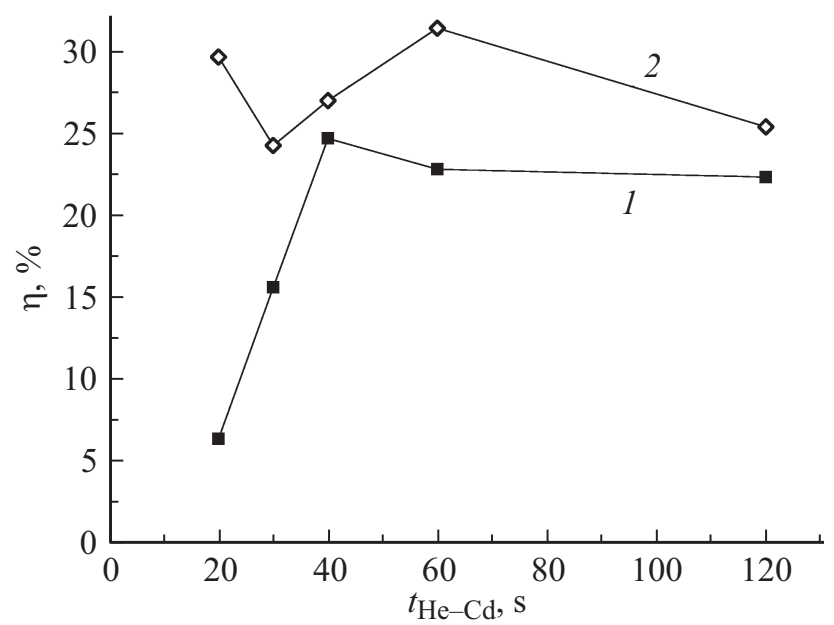

Рис. 3. Зависимость ДЭ 1-го порядка от времени экспонирования БХЖ когерентным излучением для проявленных подложек ПММА (образец № 3): эксперимент (1), расчет по теории тонких голограмм с синусоидальным профилем рельефа (2).

тивность применения проявителя, содержащего МИБК. Как видно из рис. 3, решетки на подложке ПММА при освещении $\mathrm{He}-\mathrm{Ne}$-лазером с длиной волны $0.63 \mu \mathrm{m}$ демонстрируют высокие значения ДЭ, приблизительно соответствующие ее значениям, полученным по формуле теории тонких рельефно-фазовых голограмм [1].

\section{Заключение}

Результаты проведенных исследований показали возможность эффективного переноса голографической рельефной структуры со слоя БХЖ на материал подложки из органического полимера ПММА при последовательном осушествлении технологии обработки слоев
БХЖ и технологии обработки резистов. Воздействие коротковолнового УФ излучения как на слои БХЖ, так и на ПММА позволило создать регулярные решетки с высотой рельефа порядка $1 \mu \mathrm{m}$ и более, что вполне достаточно для получения высокой ДЭ в видимой и инфракрасной областях спектра.

\section{Список литературы}

[1] Гуляев С.Н., Ратушный В.П. // Оптический журнал. 2003. T. 70. № 2. C. 45-49. [Gulyaev S.N., Ratushnyi V.P. // J. Opt. Technol. 2003. V. 70. N 2. P. $105-108$. doi: 10.1364/JOT.70.000105]

[2] Ганжерли Н.М., Гуляев С.Н., Маурер И.А. // Письма в ЖТФ. 2016. Т. 42. Вып. 19. С. 26-30. [Ganzherli N.M., Gulyaev S.N., Maurer I.A. // Techn. Phys. Lett. 2016. V. 42. N 10. P. 988-989. doi: 10.1134/S1063785016100060]

[3] Ганжерли Н.М., Гуляев С.Н., Маурер И.А. // Оптический журнал. 2017. Т. 84. № 9. С. 1-5. [Ganzherli N.M., Gulyaev S.N., Maurer I.A. // J. Opt. Technol. 2017. V. 84. N 9. P. 617-620. doi: 10.1364/JOT.84.000617]

[4] McCord M.A., Rooks M.J. Handbook of Microlithography, Micromachining and Microfabrication / Ed. by P. Rai-Choudhury. V. 1: Microlithography. Bellingham, Washington: SPIE Optical Engineering Press, 1997. P. 139-250. doi: $10.1117 / 3.2265070$

[5] Моро У. Микролитография. М.: Мир, 1990. Ч. 1. 605 с. Ч. 2. $632 \mathrm{c}$.

[6] Haiducu M., Rahbar M., Foulds I.G., Johnstone R.W., Sameoto D., Parameswaran M. // J. Micromech. Microeng. 2008. V. 18. № 11. P. 115029. doi: $10.1088 / 0960-1317 / 18 / 11 / 115029$

[7] Johnstone R.W., Foulds I.G., Parameswaran M. // J. Vacuum Sci. Technol. B. 2008. V. 26. N 2. P. 682-685. doi: $10.1116 / 1.2890688$

[8] Гуляев С.Н. Фазовые голограммы на галоидосеребряных фотоматериалах. [Электронный ресурс] Режим доступа: http://www.ioffe.ru/loeg/denisyuk_seminar.html

[9] Shankoff T.A. // Appl. Opt. 1968. V. 7. N 10. P. 2101-2105. doi: 10.1364/AO.7.002101

[10] Rooks M.J., Kratschmer E., Viswanathan R., Katine J., Fontana R.E. Jr., MacDonald S.A. // J. Vacuum Sci. Technol. B. 2002. V. 20. N 6. P. 2937-2941. doi: 10.1116/1.1524971

[11] Hoole C.F., Welland M.E., Broers A.N. // Semiconductor Science and Technology. 1997. V. 12. N 9. P. 1166-1170. doi: $10.1088 / 0268-1242 / 12 / 9 / 017$ 